\title{
Electronic Data Interchange and Enterprise Resource Planning Technology in Supply Chain Contracts
}

\author{
J. Reed Smith \\ Indiana University \\ jrsmith2@iupui.edu \\ Jeffrey Yost \\ Charleston Southern University \\ jyost@csuniv.edu \\ Harold Lopez* \\ University of Chile \\ harold.lopez@fen.uchile.cl
}

January 27, 2020

${ }^{*}$ Correspondence to Harold Lopez, University of Chile, Diagonal Paraguay 257, Santiago de Chile, Chile, Tel.+56 229783331 .

This is the author's manuscript of the article published in final edited form as:

Smith, J. R., Yost, J., \& Lopez, H. (2020). Electronic data interchange and enterprise resource planning technology in supply chain contracts. Computers \& Industrial Engineering, 142, 106330. https://doi.org/10.1016/j.cie.2020.106330 


\begin{abstract}
We examine a model of supply chain contracting with a purchaser that desires to acquire as much of a product as possible at as low a price as possible. The supplier in our model has private information about its limited capacity. We compare two models of information. In the first, the supplier observes capacity and reports the capacity to the purchaser in exchange for a purchase commitment. We designate this contract as the "Supply Chain" contract. In the second, the purchaser is directly linked to the supplier's ERP system using Electronic Data Interchange (EDI). This linkage avoids information asymmetry. We refer to this contract as the "Full Information" contract. While the Full Information contract is economically more efficient, the supplier would be reticent to agree to this contract. We propose a third contract, which we call the "Hybrid" contract, that awards the purchaser the efficiency gains available in the Full Information contract, but which provides the supplier the same profits as in the Supply Chain contract. The purchaser, however, would still prefer the Full Information contract to the Hybrid contract. We then add an additional dimension to the problem by allowing the supplier to invest in capacity. We find that due to the increased investment under the Hybrid contract, the purchaser may actually prefer the Hybrid contract to the Full Information contract - as long as the information asymmetry is not too great.
\end{abstract}

Keywords: Supply-chain management; Productive capacity; EDI; Production information; Contracts; SCM practices

JEL Classification: L23; M11; M21; M41; O33. 


\section{Introduction}

Supply chain partners share information with each other in order to improve the efficiency of production and logistics. The degree to which partners share information, however, may vary greatly from one relationship to another. In the extreme, suppliers might provide their supply chain purchasers with direct access to capacity and production information. Many Wal-Mart suppliers, for example, allow the retailer complete access to production information by allowing Wal-Mart to connect directly, using electronic data interchange (EDI), with their Enterprise Resource Planning (ERP) systems. While such arrangements undoubtedly improve productive efficiency, they are not necessarily in the best interest of both the supplier and the purchaser. As Fishman (2006) notes:

'While the kind of pressure Wal-Mart can bring to bear is, at this point, well publicized, what almost no one outside the world of Wal-Mart and its suppliers sees and understands is the high cost of those low prices. Wal-Mart has the power to squeeze profit-killing concessions from suppliers, many of whom are willing to do almost anything to keep the retailer happy, in part because Wal-Mart now dominates consumer markets so thoroughly that they have no choice'. (page 89).

This comment suggests that the purchasing leverage exerted by Wal-Mart can diminish the profit-earning potential of Wal-Mart suppliers. This diminished earnings potential, in turn, can decrease the incentives that these suppliers have to invest in their products.

We examine a stylized model of information sharing and investment. In our model, a supplier has limited capacity and private information about that capacity. That capacity can be allocated between producing for a specific purchaser (our focus purchaser) and the remaining market of anonymous purchasers. We characterize and contrast two distinct information-sharing structures. In the first, the supplier communicates capacity infor-

mation with the purchaser in exchange for the purchaser's commitment to a schedule of purchase quantities and prices. We view this information structure as reflective of many 
existing supply chain relationships and, therefore, refer to this information structure as the Supply Chain contract. A key characteristic of this relationship is that the supplier explicitly reports its capacity, which allows the supplier to earn information rents from the purchaser for sharing information.

In our second information sharing structure, we assume that the purchaser, as in the Wal-Mart example, is plugged directly into the supplier's information system. In this situation, the purchaser does not depend upon a report from the supplier. Instead, they are equally well-informed. The purchaser learns the supplier's capacity when the supplier does. Hence, we refer to this information structure as the Full Information contract. The Full Information contract provides superior economic efficiency because the information asymmetry is eliminated. But this information structure is inferior from the perspective of the supplier. The purchaser not only captures the information rents formerly earned by the supplier, but enjoys the benefit of all of the economic efficiency gains as well. As a result, suppliers that are currently engaged in a Supply Chain contract that provides information rents would be reticent to change to a Full Information contract that is characterized by strictly lower profits. ${ }^{1}$

We address this dilemma by proposing a Hybrid contract that offers both the supplier and the purchaser an improvement over the Supply Chain contract. ${ }^{2}$ In this alternative contract, the supplier allows the purchaser direct access to its capacity information. Technologically, this access might be achieved by allowing the purchaser to connect to the supplier's ERP system. In our Hybrid contract, the supplier earns precisely the same profit for each realization of capacity that it would have under the Supply Chain contract. The advantage to the purchaser is that the contract provides for an exchange of more product and over a larger range of capacity realizations than does the Supply Chain

\footnotetext{
${ }^{1}$ In fact, in our model, the supplier earns the identical profits that it would have earned if no units were sold to the purchaser.

${ }^{2}$ Actually, the contract provides the purchaser strict improvements over the Supply Chain contract while keeping the supplier indifferent. This contract could be perturbed very slightly to provide strict improvements to both parties.
} 
contract. Thus, the efficiency gains accrue to the purchaser, while the supplier is not forced to relinquish the profits it earns under the Supply Chain contract.

Note that information technology makes the Full Information and the Hybrid contracts possible. By permitting the purchaser access to the supplier's ERP information regarding capacity, the supplier does not have to observe capacity and then report. Instead, the supplier merely allows the purchaser to observe capacity directly. ${ }^{3}$ In this way, the information asymmetry can be eliminated.

In the case of a purchaser with significantly more negotiating power, as in the case of a large retailer, the purchaser may still not find this arrangement satisfactory and might demand more concessions from the supplier. In the extreme, the purchaser may be unwilling to deviate from the Full Information contract. For this reason, we examine circumstances under which the purchaser would prefer the Hybrid contract to the Full Information contract. In other words, we ask what features of the environment might make the Hybrid contract preferable to both parties. One answer to this question is that the superior profits for the supplier which derive from the Hybrid contract provide greater incentives for the supplier to invest in the product being sold to the purchaser, and this investment might affect the profits available to both parties.

To examine these incentives, we add an investment decision to our interaction. The supplier can expend resources to invest in capacity. This investment, which we assume is known to all, shifts the entire distribution of capacity realizations to the right. And because the Hybrid contract provides greater incentives for investment than does the Full Information contract, we find that the relative increase in the size of the "pie" can make the purchaser prefer the Hybrid contract to the Full Information contract. Specifically, if the degree of information asymmetry is sufficiently low, the increase in investment makes the Hybrid contract more profitable for both parties.

\footnotetext{
${ }^{3}$ Access to the supplier's ERP system can be restricted to those domains that are relevant for the contract between the two parties.
} 
Our paper relates to a growing literature in supply chain contracting. Using the classification by Colicchia et al. (2017) for information sharing in supply chain, our model would belong to the clusters "Asymmetric information in the supply chain" and "Information sharing for improved supply chain resilience". More directly related, Baiman and Rajan (2002a) provide a useful overview of the relationship between contract structures and the inter-firm incentive issues and relationships that frequently arise in supply chain partnerships. They note that incomplete contracts are frequently more descriptive of perpetual relationships in which many contract details are not resolved in a single period, but that some important Supply Chain contract issues, such as whether to outsource and how to organize suppliers, can legitimately be examined in a complete contracting setting. As our paper deals primarily with information sharing in procurement, we believe that complete contracts are appropriate for our analysis.

Baiman and Rajan (2002b) examine how information sharing may lead to opportunism on the part of the previously uninformed party. In their model, the buyer can invest in innovation and provide private production information to the supplier that the supplier can possibly exploit. However, they do not compare their setup to a straightforward, arms-length transaction, which is the primary focus of our paper. Cachon and Fisher (2000) develop an information sharing model with N identical retailers and one supplier. They compare a standard supply chain model with a full information model with inventory holding costs and back-order penalty costs. In a numerical example they find the costs going down between $2.2 \%$ and $12.1 \%$ for the full information contract.

Baiman, Fischer, and Rajan (2000) examine a buyer-supplier relationship where the quality of the product is the basis of the contract. Their analysis examines a double moral-hazard setting where the supplier incurs unobservable quality costs and the buyer incurs unobservable quality appraisal costs. Essentially, the two parties share the responsibility for providing a quality product to the market. They further provide some insights into information sharing that can reduce the inefficiency caused by the information asymmetry. These results were extended in Baiman, Fischer, and Rajan (2001). 
In this study, the authors examine the balanced scorecard issue of measuring internal processes by contracting internal and external failure rates.

Narayanan, Raman, and Singh (2005) and Arya and Mittendorf (2007) examine issues similar to that in our paper in the sense that both of these papers examine a tension between alternative uses of production capacity. Narayanan et al. (2005) examine the benefit of supplier insurance in an environment in which two purchasers compete for consumers. They demonstrate that by subsidizing leftover inventory, they can reduce the intensity of competition between buyers and, therefore, maintain a higher market price for the product. Our model incorporates a similar feature. By dividing capacity between sales to the purchaser (through a single contract) and to the remaining market, the supplier can maintain a higher overall price for his production. Of course, we examine the purchaser's problem of procurement rather than the supplier's problem of revenue maximization. In this sense, our paper more resembles Arya and Mittendorf (2007) who examine the interplay between internal procurement and external procurement. They demonstrate that the agency costs inherent in internal procurement can improve the negotiating position of the procuring firm when negotiating with an external source. We examine the opposite problem. In our model, the purchaser is competing for capacity with external purchasers. But in both models, the purchaser is a lesser-informed party in the procurement contract. Heese and Kemahlioğlu-Ziya (2016), in turn, a dishonest retailer faces incentives to cheat about her sales revenues. The authors prove that in some scenarios, the supplier actually benefits from a cheating retailer.

Titah et al (2016) investigate whether information integration is always beneficial for firms. The authors show that full integration is optimal in a centralized decision making setting for supplier and retailer. However, when firms act strategically, no information is preferred. In this paper we propose a middle ground approach in which some information is shared, but not all, being either indifferent or preferable by both parties. More importantly, generating incentives to invest on capacity for the supplier that were absent in the full information setting. Lin and He (2019) show that the type of supply chain 
contract between a supplier and a retailer affects the optimal financing decision for a capital constrained supplier. Simchi-Levi and Zhao (2003) study the value of information sharing between the supplier and a retailer when the later has information about the product demand. In their model the potential gains are driven by a better policy to schedule production. The authors show that the benefits of information sharing depends on the frequency of the sharing and the manufacturer's production capacity. In our model, the private information is precisely the available capacity by the supplier, who decides whether to share it with the retailer.

In fact, most of information sharing literature focus on information about product demand (see Rached et al. 2015). For instance, Huang et al. (2017) study the impacts of information sharing on inventory reduction and profit gains in a setting where the retailer may or may not share demand information with multiple suppliers. In their model, if there is no information being shared, the suppliers may infer demand information from the retailer's past orders when the demand is time-correlated. The authors show that sharing demand information with the suppliers can reduce the inventory bullwhip effect, reducing inventory levels and increasing retailer's gains. In this sense, Ding et al. (2011) study the upstream profit sharing of the gains from information sharing. The authors use a cooperative game approach to show the benefits of sharing information in a threeechelon supply chain with inventory holding costs for the manufacturer, distributors and retailers. Again, the information sharing mechanism is through the retailer-distributormanufacturer orders.

Our paper deals with the under studied topic of information sharing about capacity. Dominguez et al. (2019) study a closed-loop supply-chain model that integrates both manufacturing and remanufacturing, finding that the capacity constrains play a key role on contracting and pricing. In a model explicitly dealing with capacity constraints for a supply chain with multiple retailers, Helper et al. (2010) study alternative information sharing strategies. In particular, the information to be shared is about customer demand and/or inventories withheld by the retailer, while the capacity vector is known by all 
parties. In two simulation studies, Chen et al. (2007) and Yu et al. (2010) find among different combinations of information sharing, that sharing information about capacity may lead to higher supply chain costs. In our model and posterior numerical example, we show that those shortcomings can be overcome by designing a Hybrid contract between the full information and no information contracts. When business complexity is taken into account, Welker et al. (2008) find that capacity information is shared among companies in complex environments through ERP systems, in their empirical study on the influence of business conditions on supply chain information-sharing mechanisms. Our model provides theoretical foundations for such results.

The remainder of this paper is organized as follows. Section 2 describes and characterizes the product procurement problem facing the purchaser and characterizes both the Supply Chain contract, in which the supplier observes capacity and then communicates this value to the purchaser, and the Full Information contract, in which the purchaser has direct access to the supplier's capacity information. We then compare these two contracts in terms of the quantity of goods sold to the purchaser, the price that the purchaser pays for these goods, and in terms of the expected profits of the purchaser and supplier. In section 3, we describe a Hybrid contract that provides the same payoffs to the supplier for each capacity realization as does the Supply Chain contract, but which provides efficiency gains that accrue to the purchaser. We also compare this contract to the Supply Chain contract and the Full Information contract. We consider the supplier's capacity investment decision in section 4 and illustrate our results with a numerical example in section 5. We provide concluding remarks in section 6 . 


\section{Product procurement problem and contract char- acteristics}

Consider a firm that relies on a critical component or product that is produced by a single firm. We refer to this purchaser as our focus purchaser. The supplying firm has limited capacity to produce this product and the purchasing firm must compete for these capacity resources. We begin by describing the production and marketing environment facing the supplier without consideration of the sales to the purchaser.

The supplier has capacity of $K$ for producing the product, but $K$ is privately observed. The purchaser knows only the distribution of possible values of $K: K \sim U[\underline{K}, \underline{K}+\Delta]$, where $\underline{K}$ and $\Delta$ are parameters. ${ }^{4}$ We assume that the supplier faces two sources of demand for their product: a contracted purchase by our focus purchaser and a linear demand for their product that is offered to all remaining market participants. Specifically, we assume the price, $P(x)$ that their product brings, as a function of the number of units $(x)$ that are sold, is given by the following linear demand function.

$$
P(x)=A-b x
$$

As each unit has a cost of $c$ to produce, the profit earned from these sales, $\Pi_{S}(x)$, is the total revenue less the cost of production.

$$
\Pi_{S}(x)=x(A-b x)-c x
$$

\footnotetext{
${ }^{4}$ While each of our models can be characterized for more general density functions, the assumption that capacity is uniformly distributed over a closed interval makes the comparison across different information structures more transparent and improves the intuition. We consider $\underline{K}$ to be exogenous in sections 2 and 3 . In section 4 , we extend the model to allow the investor to invest in capacity, which will make this variable endogenous.
} 
In the absence of any capacity considerations, the firm would maximize profits by producing and selling $x^{*}$ units where

$$
x^{*}=\frac{A-c}{2 b}
$$

Given capacity constraints, though, the supplier will produce and sell all $K$ units unless $K>\frac{A-c}{2 b}$.

The purchaser desires to purchase as many units as possible in a negotiated sale with the supplier and obtains a benefit (either from external sales or from further converting the product) of $V$ per unit purchased. The contract specifies a payment $T$ for each possible transfer of $y$. For each transfer amount $y$ and payment $T$, the benefit to the purchaser is $V y-T^{5}$

When the supplier learns the value of $K$, it reports a value $\hat{K}$ to the purchaser. The purchaser then pays the contract price and the supplier provides the contract amount of the product $y$. Since there is no monitoring, the truthfulness of the report $\hat{K}$ must be self-enforcing.

Before proceeding to purchaser's problem, we first note that the supplier earns economic rents from its superior information. These rents, which will be useful in characterizing the contracting problem facing the purchaser, are defined below.

$$
r(\hat{K} \mid K)=T(\hat{K})+\Pi_{S}(K-y(\hat{K}))-c \cdot y(\hat{K})-\Pi_{S}(K),
$$

\footnotetext{
${ }^{5}$ We recognize that there is an apparent inconsistency between our assumptions that the supplier faces a linear demand curve for the product while the purchaser treats the product as a competitive commodity. This assumption greatly simplifies our analysis. In addition, we believe that for a retailer, a single product offering frequently is viewed as a commodity. It really comes down to scale. From Wal-Mart's perspective, Huffy bicycles are just bicycles, whereas to Huffy, they are (or were) their sole focus.
} 
where $\Pi_{S}(\cdot)$ is defined by equation (2). This expression recognizes the fact that the value of the information held by the supplier equals the difference between its total profit under the contract (profit on outside sales plus the profit from the sale of $y$ units to the purchaser) and the profit that it would have earned had it sold exclusively to external customers. The term, $r(\hat{K} \mid K)$ reflects the fact that the rents depend upon the reported capacity level, $\hat{K}$, as well as the actual value of $K$. Note that both $T(\hat{K})$ and $y(\hat{K})$ depend upon the reported value, $\hat{K}$.

We now describe the purchaser's contracting problem in the following constrained optimization program.

$$
\begin{gathered}
\max _{T(y(\hat{K})), y(\hat{K})} M=\int_{\underline{K}}^{\underline{K}+\Delta}[V y(k)-T(y(k))] \frac{1}{\Delta} d k \\
\text { subject to } r(K)=r(K \mid K) \geq 0 \forall K \in[\underline{K}, \underline{K}+\Delta] \\
r(K) \geq r(\hat{K} \mid K) \forall \hat{K} \in[\underline{K}, \underline{K}+\Delta], K \in[\underline{K}, \underline{K}+\Delta], \hat{K} \neq K
\end{gathered}
$$

Constraint (6) requires that $r(K)$, the economic rent of reporting $\hat{K}=K$ when $K$ is observed, is weakly positive. In other words, the supplier's total profit (from external sales and from sales to the purchaser) for all possible values of $K$ must be at least as high as if it just sold externally.

Constraint (7) requires that for every possible observation of $K$, there is no announcement, $K^{\prime} \neq K$, such that the total profit to the supplier is strictly higher by reporting $K^{\prime}$ than it is if it reports honestly $(K)$. For expositional purposes, we refer to the solution to this program as the Supply Chain contract and will employ the superscript, SC.

We now characterize the solution to the Supply Chain contract described in expressions (5), (6), and (7). The supplier observes $K$ and reports $\hat{K}$. The Truth-Telling constraint (constraint (7)) requires that, given the supplier observes $K$, the truthful report $\hat{K}=K$ yields a (weakly) higher profit than any possible dishonest report $\hat{K} \neq K$. Algebraically, 
this requires that the $\left(y^{S C}(\hat{K}), T^{S C}(\hat{K})\right)$ contract offered by the purchaser makes $\hat{K}=K$ at least weakly optimal for the supplier.

The supplier desires to maximize the following condition by its choice of $\hat{K} \in[\underline{K}, \underline{K}+\Delta]$ :

$$
r(\hat{K} \mid K)=T(y(\hat{K}))+A(K-y(\hat{K}))-b(K-y(\hat{K}))^{2}-c K-\Pi_{S}(K)
$$

For each $\hat{K}$ that the supplier reports, the purchaser requests a contracted amount of $y$ and gives the supplier a contracted price, $T$. The first component of equation (8) is the price. The second two components combine to yield the revenue from outside sales that the supplier will earn on whatever capacity remains after providing the sale of $y(\hat{K})$ units to the purchaser. Since the supplier is producing at capacity it incurs total cost, $c K$. Finally, the rent payment that the supplier is attempting to maximize is the difference between these two sources of profit and the profit that it would have earned in the absence of sales to the purchaser, $\Pi_{S}(K)$. This reservation profit is $A K-b K^{2}-c K$. Proposition 1 characterizes the equilibrium contract.

Proposition 1. The equilibrium contract in which the supplier truthfully communicates capacity to the purchaser is characterized by the following transfer amount, $y^{S C}(\hat{K})$ and payment, $T^{S C}(\hat{K})$.

$$
y^{S C}(\hat{K})=2 \hat{K}-\underline{K}-\Delta-\frac{A-V}{2 b}
$$

as long as $K$ is greater than or equal to the average of $\underline{K}+\Delta$ and $\frac{A-V}{2 b}$. Otherwise, no units will be sold to the purchaser. The payment to the supplier is computed as:

$$
T^{S C}(\hat{K})=\frac{1}{8 b}(3 V+A+2 b(2 \hat{K}-3(\underline{K}+\Delta)))(V+2 b(2 \hat{K}-(\underline{K}+\Delta))-A)
$$

(proof in appendix) 
We now turn to a Full Information contract in which the supplier and purchaser are equally well informed prior to contracting. This case reflects a situation where the purchaser has direct access to the supplier's capacity information through EDI.

In this contract, both the supplier and the purchaser observe the value of $K$. The purchaser then offers to purchase $y^{F I}$ units from the supplier for a price, $T^{F I}$. $T^{F I}$ must provide the supplier with sufficient compensation to cover the opportunity cost of not selling those units externally, but does not include any information rents. The supplier's opportunity cost is given by the following condition:

$$
\Pi_{S}(K)=A K-b K^{2}-c K
$$

which implies:

$$
T^{F I}-y^{F I}\left(A-b\left(2 K-y^{F I}\right)\right) \geq 0
$$

We will denote these optimal values with a superscript $F I:\left(y^{F I}, T^{F I}\right)$. The purchaser will choose $y^{F I}$ to maximize $V y^{F I}(K)-T^{F I}(K)$ where $T^{F I}(K)$ is the price that solves (12) as an equality. Proposition 2 characterizes the optimal choices of the Full Information contract.

Proposition 2. The following choices define the contract between the purchaser and the supplier under the Full Information contract.

$$
\begin{gathered}
y^{F I}(K)=K-\frac{A-V}{2 b} \\
T^{F I}(K)=\frac{(A-2 b K+V)(-A+2 b K+V)}{4 b} \text { if } K \leq \frac{A-c}{2 b}
\end{gathered}
$$


and

$$
T^{F I}(K)=\frac{1}{4 b}\left(V^{2}-c(2 A-c-4 b K)\right) \quad \text { if } \quad K>\frac{A-c}{2 b}
$$

(proof in appendix)

Since the Full Information contract provides the supplier with a payoff exactly equal to their reservation utility, and since that reservation utility is a constant beyond the profit maximizing level of $K=\frac{A-c}{2 b}$, the price paid under the Full Information is different for $K \leq \frac{A-c}{2 b}$ and for $K>\frac{A-c}{2 b}$.

We now compare the Full Information contract and the Supply Chain contract in terms of the quantity of product sold to the purchaser, the price of the transaction, and the relative profits to the purchaser and supplier. We begin by comparing the amount of product that is sold to the purchaser. To do this, we first compute the capacity level under each contract below which no product is sold to the purchaser. We denote these values $K^{S C}$ and $K^{F I}$ for the Supply Chain contract and the Full Information contract respectively.

Under the Supply Chain contract, no product is sold to the purchaser if:

$$
K \leq K^{S C}=\frac{A+2 b(\underline{K}+\Delta)-V}{4 b}
$$

and under the Full Information contract, no product is sold to the purchaser if:

$$
K \leq K^{F I}=\frac{A-V}{2 b}
$$


These values are determined by the values of $K$ for which $y$, under each of the two contracts, is non-positive. Solving for $y$ in (9) equal to zero as a function of $K$ yields $K^{S C}$ in (16) and solving for $y$ in (13) as a function of $K$ yields $K^{F I}$ in (17).

The Full Information contract allows the purchaser to find the price-quantity combination that just covers the loss of sales to the external market. In the Supply Chain contract, the purchaser must cover these losses and must also provide the supplier information rents. As a result, $K^{S C}>K^{F I}$. Our next result, Corollary 1, formalizes this result.

Corollary 1. For all values of $K \in\left(\frac{A-V}{2 b}, \underline{K}+\Delta\right), y^{F I}>y^{S C}$.

(proof in appendix)

This result follows directly from the comparison of the value of $y^{S C}$ in (9) and the value of $y^{F I}$ in $(13)$.

A more relevant comparison between the different contracts is a comparison of the expected profits obtained by the supplier and the purchaser under each contract alternative. This result is presented in Proposition 3.

Proposition 3. The expected profit to the purchaser is higher under the Full Information contract than under the Supply Chain contract and the expected profit to the supplier is higher under the Supply Chain contract than it is under the Full Information contract.

(proof in appendix)

The expected profit to the purchaser is higher under the Full Information contract for two reasons. First, there is an increase in economic efficiency because more units are sold over a greater range of capacity realizations. In addition, though, the purchaser is able to avoid the information rents that were paid to the supplier under the Supply Chain contract. From the perspective of the supplier, the Full Information contract is less advantageous than the Supply Chain contract precisely because of the loss of these 
information rents. In fact, the Full Information contract makes the supplier indifferent, at every value of $K$, between accepting and rejecting the contract.

The supplier clearly would prefer a different contract than would the purchaser. As we are attempting to derive contracts that both parties would find agreeable, our first step will be to propose a contract that provides the purchaser a strict payoff improvement for the purchaser at no cost to the supplier. This improvement is achieved by exploiting the technological environment that allows the purchaser direct access to the supplier's capacity information with a caveat that the purchaser only retains such access if it is willing to agree to this compromise contract. We refer to this as the Hybrid contract.

\section{Hybrid Contract}

In this section, we propose a Hybrid contract that the supplier would approve and that would provide the purchaser with strictly greater profits. The idea is straightforward. We compute the profit that the supplier would earn under the Supply Chain contract for each realization of capacity. We then ask the supplier to provide the same number of units that it would under the Full Information contract. We then impute the price that makes the supplier indifferent between this Hybrid contract and the Supply Chain contract that we characterized in Proposition 1.

The profit to the supplier is computed as $T R[K-y]+T-c K$ where $T R[x]=x(A-b x)$. For a given realization of $K$, if the supplier provides $y^{F I}=K-\frac{A-V}{2 b}$ units to the purchaser for $T^{H}$ and sells the remaining $\frac{A-V}{2 b}$ units to the external market, it obtains an overall profit of:

$$
T^{H}+\frac{A^{2}-V^{2}}{4 b}-c K
$$


Under the Supply Chain contract, the supplier's profit for $K \geq K^{S C}=\frac{A-V}{4 b}+\frac{\underline{K+\Delta}}{2}$ is computed as:

$$
\begin{aligned}
& \frac{1}{8 b}\left(A^{2}+4 b^{2}\left(2 K^{2}-4 K(\underline{K}+\Delta)+(\underline{K}+\Delta)^{2}\right)\right)+ \\
& \frac{1}{8 b}\left(A(4 b(\underline{K}+\Delta)-2 V)+V^{2}+b(8 K V-4(\underline{K}+\Delta) V)\right)-c K
\end{aligned}
$$

For $K<K^{S C}$, the supplier's profit is:

$$
K(A-b K)-c K
$$

By equating the profits computed in (18) and (19) and solving for $T^{H}$, we obtain the price function of the Hybrid contract over the range, $K \in\left[K^{S C}, \underline{K}+\Delta\right]$ and by equating the profits in (18) and (20), we obtain the price function over the range, $K \in\left[\underline{K}, K^{S C}\right)$. The quantity is just $y^{H}=y^{F I}=K-\frac{A-V}{2 b}$ for $K \geq K^{F B}=\frac{A-V}{2 b}$. Since the capacity is observable under the Hybrid contract, the argument is $K$ rather than $\hat{K}$ as in the Supply Chain contract. This contract is described in Proposition 4.

Proposition 4. By construction, the Hybrid contract, $\left(y^{H}(K), T^{H}(K)\right)$ is characterized by: 6

$$
\begin{gathered}
y^{H}(K)=y^{F I}(K)=K-\frac{A-V}{2 b} \\
T^{H}(K)=\frac{(V+A-2 b K)(V-A+2 b k)}{4 b}, \quad \text { if } K \in\left[K^{F I}, K^{S C}\right] \text { and } \\
T^{H}(K)=\frac{(A-4 b K+2 b \underline{K}-V)^{2}}{8 b}+\frac{(V+A-2 b K)(V-A+2 b k)}{4 b} \\
\text { if } K \in\left[K^{S C}, \underline{K}+\Delta\right]
\end{gathered}
$$

\footnotetext{
${ }^{6}$ Since this contract is constructed by equating (18) and (19), we do not provide a formal proof of the steps. The details are available from the authors.
} 
This contract is identical to the Full Information contract for all $K \in\left[\underline{K}, K^{S C}\right]$. Since no units would be sold to the purchaser under the Supply Chain contract for these capacity realizations, the Hybrid contract must merely satisfy the lost opportunity of the supplier. For $K>K^{S C}$, the Hybrid contract requires more units to be sold than under the Supply Chain contract, but the price paid for those units is greater than even that provided by the Supply Chain contract. This result is formalized as Corollary 2.

\section{Corollary 2.}

$$
T^{H}(K)>T^{S C}(K) \quad \forall \quad K \in\left(K^{S C}, \underline{K}+\Delta\right)
$$

(proof in appendix)

The Hybrid contract that we described in Proposition 4 is strictly preferred by the purchaser to the Supply Chain contract that we described in Proposition 1 for every observation of $K$ whereas the supplier is indifferent to the two contracts. This result is stated as Proposition 5.

Proposition 5. For each realization of capacity, $K>K^{F B}=\frac{A-V}{2 b}$, the supplier is indifferent between the Hybrid contract and the Supply Chain contract and the purchaser prefers the Hybrid contract to the Supply Chain contract.

(proof in appendix)

Proposition 5 establishes that both supply chain partners would (weakly) prefer the Hybrid Contract to the Supply Chain contract. As a result, if the two firms were engaged in a relationship with the Supply Chain contract, both parties would be willing to renegotiate and agree upon this contract (the Hybrid contract) whereas agreement upon the Full Information contract is unlikely, since the supplier's profits would decrease. The advantage to this contract is that it improves efficiency relative to the Supply Chain contract and offers the same efficiency as the Full Information contract. The purchaser, under the Hybrid contract, reaps the benefits of improved efficiency, while the supplier is kept harmless. 
Even though the Hybrid contract is an improvement for the purchaser, the purchaser still prefers the Full Information contract over the Hybrid contract. A natural question, therefore, is whether there are circumstances under which both parties prefer the Hybrid contract. We find that if we allow the supplier to invest in capacity, then the incentives to invest are greater for the Hybrid contract than they are for the Full Information contract. As a result, the resulting expected payoff to the purchaser and supplier may be greater under the Hybrid contract.

In the next section, we relax our assumption that $\underline{K}$ is exogenous and allow the supplier to choose this parameter at a cost, $Z * \underline{K}$. Of course, the incentives to invest in $\underline{K}$ depend upon the contract. The Supply Chain and Hybrid contracts provide greater incentives to invest in capacity.

\section{Capacity investment}

Recall that $K \sim U[\underline{K}, \underline{K}+\Delta]$. We assume now that the supplier can shift this distribution to the right by investing in capacity. Specifically, we allow the supplier to choose the value of $\underline{K}$ at a cost, $Z * \underline{K}$. We assume that this choice is common knowledge (observable).

With this assumption, we can compute the expected payoff to the supplier, as a function of $\underline{K}$ for each of the two contracts (Hybrid and Full Information). For the Full Information contract, (13), (14), and (15) characterize $\left(y^{F I}, T^{F I}\right)$. Using these values, we compute the expected payoff to the supplier as:

$$
\int_{\underline{K}}^{K^{F I}} K(A-b K-c) \frac{1}{\Delta} d K+\int_{K^{F I}}^{\underline{K}+\Delta}\left(T^{F I}+\left(\frac{A-V}{2 b}\right)-c K\right) \frac{1}{\Delta} d K
$$

where $T^{F I}$ is given by (14) if $K \leq \frac{A-c}{2 b}$ and by (15) if $K>\frac{A-c}{2 b}$. Substituting and integrating (25), we obtain: 


$$
\begin{aligned}
& \frac{1}{12 b^{2} \Delta}\left(A^{3}-3 A^{2} c-c^{3}+6 b^{2} c \underline{K}^{2}+4 b^{3} \underline{K}^{3}+3 A\left(c^{2}-2 b^{2} \underline{K}^{2}\right)\right) \\
& +\frac{(A-c)^{2}}{8 b^{2} \Delta}(2 b(\underline{K}+\Delta)-A+c)-Z \underline{K}
\end{aligned}
$$

We find the supplier's optimal investment choice, $\underline{K}^{F I}$, by taking the derivative of (26) with respect to $\underline{K}$ and solving that expression equal to zero. That yields the following optimal choice:

$$
\underline{K}^{F I}=\frac{A-c}{2 b}-\sqrt{\frac{\Delta Z}{b}}
$$

Using the same approach, the expected payoff to the supplier under the Hybrid contract is:

$$
\int_{\underline{K}}^{K^{F I}} K(A-b K-c) \frac{1}{\Delta} d K+\int_{K^{F I}}^{\underline{K}+\Delta}\left(T^{H}+\left(\frac{A^{2}-V^{2}}{4 b}\right)-c K\right) \frac{1}{\Delta} d K
$$

where $T^{H}$ is given by (22) if $K \in\left[K^{F I}, K^{S C}\right]$ and (23) otherwise.

Note, however, that the value of $K^{S C}=\frac{1}{2}\left(\frac{A-V}{2 b}+(\underline{K}+\Delta)\right)$ depends upon $\underline{K}$.

Using the same approach as we did for the Full Information contract, we obtain the following optimal choice of $\underline{K}^{H}$ under the Hybrid contract:

$$
\underline{K}^{H}=\frac{A-V}{2 b}+3 \Delta-2 \sqrt{\frac{\Delta(c+3 b \Delta-V+Z)}{b}}
$$

Next, we take the values of $\underline{K}^{F I}$ in (27) and $\underline{K}^{H}$ in (29) and substitute these values into the expected payoff functions for the purchaser under the Full Information contract and the Hybrid contract, respectively, and compare those expected values. The expected payoff for the purchaser under the Full Information contract is computed as: 


$$
\int_{K^{F I}}^{\underline{K}^{F I}+\Delta}\left(V\left(K-\frac{A-V}{2 b}\right)-T^{F I}\right) \frac{1}{\Delta} d K
$$

where $T^{F I}$ is given by (14) if $K \leq \frac{A-c}{2 b}$ and by (15) if $K>\frac{A-c}{2 b}$ and $\underline{K}^{F I}$ is given by (27). Similarly, the expected payoff for the purchaser under the Hybrid contract is computed as:

$$
\int_{K^{F I}}^{\underline{K}^{H}+\Delta}\left(V\left(K-\frac{A-V}{2 b}\right)-T^{H}\right) \frac{1}{\Delta} d K,
$$

where $T^{H}$ is given by (22) if $K \in\left[K^{F I}, K^{S C}\right]$ and (23) if $K>K^{S C}$, and $\underline{K}^{H}$ is given by $(29) \cdot{ }^{7}$

The purchaser would prefer the Hybrid contract, with the level of investment that results, $\underline{K}^{H}$ to the Full Information contract, with the resulting investment of that contract, whenever the expected payoff in (31) is greater than that in (30). The higher the value of $\Delta$, the more uncertain is capacity and the greater the information asymmetry. If the information asymmetry is small enough and if investment in capacity is sufficiently inexpensive, then the purchaser would prefer to pay the incremental information rents in order to induce more investment in capacity. This result is formalized in Proposition 6.

Proposition 6. Suppose that the supplier can choose $\underline{K}$ at a cost of $Z \underline{K}$ and that the supplier's choice of $\underline{K}$ is observable. For a range of values of $\Delta$ and $Z$, the purchaser would prefer to enter into the Hybrid contract with the supplier than the Full Information contract.

(proof in appendix)

The range of values for which Proposition 6 holds true requires that $\Delta$ and $Z$ be relatively small. It is important that $Z$ be relatively small so that the incentives to invest

\footnotetext{
${ }^{7}$ The details of these expressions, with (13), (14), (15), (27), (22), (23), and (29) substituted into (30) and (31) are available from the authors.
} 
in capacity have noticeable effect. It is important that $\Delta$ be relatively small because larger values of $\Delta$ relate to greater information asymmetry. Greater information asymmetry relates to higher information rents for the supplier. If these information rents are too high, the investment effect is not strong enough to overcome the cost of the information rents.

The result implies that the purchaser might actually prefer to contract with the supplier using the Hybrid contract, which allows the supplier to exploit information rents, than the Full Information contract, which does not if (1) the rents are not too large and (2) the rents provide sufficient incremental incentive for investment in capacity. The important point to note here is that by including investment as an observable decision, we have changed the problem from one of choosing between contracts in a single game to one of choosing between two different games. ${ }^{8}$ In the next section, we illustrate our results with a numerical example.

\section{$5 \quad$ Numerical Example}

We begin by examining the problem without investment. We will assume that the gross benefit to the purchaser of each unit provided by the supplier is 60 . Further, we assume that demand is given by $p(x)=100-x$ and that each unit costs 10 to manufacture. Finally, we assume that $K \sim U[0,45]^{9}$. For these parameters, the three contracts are described below:

\footnotetext{
${ }^{8}$ One potential issue that we acknowledge is that once the supplier has made the capacity investment, the purchaser might prefer to recontract to the full-information contract rather than the hybrid contract. We assume that the contract includes a binding commitment by the purchaser that they will purchase from the supplier according to the pricing schedule of the hybrid contract.

${ }^{9}$ This assumption is equivalent to assuming that $\underline{K}=0$ and that $\Delta=45$.
} 


$$
\begin{aligned}
& y^{F I}=K-20 \\
& T^{F I}=(K-20)(80-K) \\
& y^{S C}=2 K-65 \\
& T^{S C}=2 K^{2}-60 K-\frac{325}{2}
\end{aligned}
$$

$$
\begin{aligned}
& y^{H}=y^{F I}=K-20 \\
& T^{H}=(K-20)(80-K) \quad \text { if } \quad K \in[20,32.5] \\
& T^{H}=K^{2}-30 K+\frac{1025}{2} \quad \text { if } \quad K \in(32.5,45)
\end{aligned}
$$

The units sold to the purchaser are illustrated in Figure 1.

\section{[INSERT FIGURE 1 ABOUT HERE]}

The dashed line represents the units sold under the Full Information contract and under the Hybrid contract. The solid line represents units sold under the Supply Chain contract. For every realization of $K$ less than $\underline{K}+\Delta$, the Full Information and Hybrid contracts yield more units in the exchange. This is the source of the economic efficiency gains that these contracts provide. The prices under the three contracts are illustrated in Figure 2.

\section{[INSERT FIGURE 2 ABOUT HERE]}

The dotted line represents the price under the Full Information contract, the dashed line represents the price under the Hybrid contract, and the solid line represents the Price under the Supply Chain contract. Note that for $K<32.5$, the price is the same under the Full Information contract and the Hybrid Contract. That is because no units are 
being sold under the Supply Chain contract. At that point, though, the price under the Hybrid contract increases above the Full Information contract and above the Supply Chain contract. This result is driven primarily by the fact that more units are being sold under the Hybrid contract. ${ }^{10}$

The profit to the supplier is shown in Figure 3.

\section{[INSERT FIGURE 3 ABOUT HERE]}

Again, the dotted line represents the Full Information contract, the dashed line represents the Hybrid contract, and the solid line (collinear with the Hybrid contract) represents the Supply Chain contract. By construction, the profits under the Hybrid contract follow the profits under the Supply Chain contract. Clearly, these contracts provide superior profits to the supplier under the Full Information contract. Note that the profits to the Supplier from all three contracts are collinear up to the point that the quantity sold under the Supply Chain contract is positive $(K=32.5)$.

The profits to the purchaser under the three contracts are shown in Figure 4.

\section{[INSERT FIGURE 4 ABOUT HERE]}

Figure 4 shows that while the profits to the Purchaser under the Full Information contract are (weakly) greater than those under the Hybrid contract, the Hybrid contract provides strictly higher profits to the purchaser than the Supply Chain contract.

We now extend our example to consider the supplier's investment in capacity. We will now assume that $Z=15$ and that $\underline{K}$ is endogenous. We will examine characteristics of the interactions over a range of $\Delta \in[15,40] .^{11}$

Substituting our numerical assumptions into (27) and (29), we obtain $\underline{K}^{F I}=45-$ $\sqrt{15 \Delta}$ and $\underline{K}^{H}=20+3 \Delta-2 \sqrt{3 \Delta^{2}-35 \Delta}$. Substituting these optimal choices into

\footnotetext{
${ }^{10}$ The price for a given level of sales to the purchaser is greater under the Hybrid contract than under the Supply Chain contract.

${ }^{11} \underline{K}^{H}$ is undefined for $\Delta \leq 35 / 3$.
} 
(30) and (31), we obtain $E\left[\Pi_{\text {Purchaser }}^{F I}\right]=625+25 \Delta-45 \sqrt{15 \Delta}$ and $E\left[\Pi_{\text {Purchaser }}^{H}\right]=$ $\frac{1}{3}\left(21 \Delta^{2}-(70+12 \Delta) \sqrt{3 \Delta^{2}-35 \Delta}\right)$. The optimal choice for the supplier is illustrated, as a function of $\Delta$, in Figure 5 .

\section{[INSERT FIGURE 5 ABOUT HERE]}

The solid line represents the supplier's capacity investment under the Hybrid contract and the dashed line represents the investment under the Full Information contract. Clearly, the investment is greater under the Hybrid contract (but the difference decreases with the magnitude of $\Delta$ ). Recall that $\Delta$ relates to the amount of information asymmetry since it defines the range of possible capacity realizations. ${ }^{12}$

The profits under the two different contracting scenarios is illustrated in Figure 6.

\section{[INSERT FIGURE 6 ABOUT HERE]}

The Purchaser's profit under the Hybrid contract, which is again represented by the solid line, is strictly greater than the profit under the Full Information contract for $\Delta \leq 38.1$ beyond which, the profit is greater under the Full Information contract. This illustrates the importance of $\Delta$ in the interaction. The higher the uncertainty, the more likely the purchaser is to prefer the Full Information contract.

\section{Conclusion}

We compare two contract forms between a supplier and the purchaser of a product. A critical feature of our model is that the supplier has private information about production capacity and an external market for the product exists. The first contract is one in which the supplier, in exchange for a purchase commitment by the purchaser, shares capacity information. This contract reflects the current practice of information sharing between

\footnotetext{
${ }^{12}$ There is, however, a mean effect as well. The larger the value of $\Delta$, the higher the expected capacity value.
} 
supply chain partners. We next consider a contract without information asymmetry. This contract might reflect an environment in which the supplier and purchaser share capacity information directly using EDI. The purchaser strictly prefers this contract to the Supply Chain contract, but the supplier suffers a significant loss in profit with this contract alternative. As a result, suppliers are unlikely to agree to these contracts even though they provide overall profit improvements.

We propose an alternative contract. This alternative yields the same total profits as the Full Information contract but divides these profits more equitably. The supplier earns the same overall profits as it does under the Supply Chain contract and the purchaser earns strictly higher profits. Of course, the ability of suppliers to negotiate such contracts depends in part on their relative power in the bargaining process. When negotiating with Wal-Mart, for example, suppliers have very little leverage.

We then show that under some circumstances, the purchaser would actually prefer the Hybrid contract to the Full Information contract. Specifically, the superior profits available to the supplier under the Hybrid contract induce greater investment in capacity and this provides improved profits for the entire relationship. The purchaser can selfishly improve its own profits by yielding information rents to the supplier. This result depends, however, on how much information asymmetry exists in the relationship. If the information asymmetry is too substantial, then the incremental profits that derive from increased investment are not enough to overcome the magnitude of the information rents that accrue to the supplier in the Hybrid contract.

Our model is restrictive in that we assume a specific form of the supplier's market opportunity and the market facing the purchaser. The incentive issues, however, are more general. The supplier is attempting to operate profitably and the purchaser wishes to obtain its products at the lowest possible cost. Information is an important strategic variable in this relationship and, to the extent that the purchaser is successful in eliminating information asymmetries, the supplier's profitability in the relationship is squeezed. 
The supplier's incentives to invest in product quality or production capacity or some other product-specific investment are consequently diminished. It is possible that both parties could find it profitable to contract creatively and allow the supplier to retain some of the profits that would be otherwise lost in an improved information structure. 


\section{References}

[1] Arya, A., and B. Mittendorf. 2007. Interacting supply chain distortions: The pricing of internal transfers and external procurement. The Accounting Review 82 (3):551-580.

[2] Baiman, S., and M. Rajan. 2002a. Incentive issues in inter-firm relationships. Accounting, Organizations, and Society 27:213-238.

[3] - 2002b. The role of information and opportunism in the choice of buyer-supplier relationships. Journal of Accounting Research 40 (2):247-278.

[4] Baiman, S., P. Fischer, and M. Rajan. 2000. Information, contracting, and quality costs. Management Science 46 (6):776-789.

[5] - 2001. Performance measurement and design in supply chains. Management Science 47 (1):173-188.

[6] Cachon, G. and M. Fisher. 2000. Supply chain inventory and the value of shared information. Management Science 46 (8):1032-1048.

[7] Chen, M., T. Yang, and C. Yen. 2007. Investigating the value of information sharing in multi-echelon supply chains. Quality \& Quantity 41 (3): 497-511.

[8] Colicchia, C., A. Creazza, C. Noè and F. Strozzi. 2017. Information sharing in supply chains: a review of risks and opportunities using the systematic literature network analysis (SLNA). Supply Chain Management: An International 24 (1): 5-21.

[9] Dominguez, R., B. Ponte, S. Cannella and J. Framinan. 2019. On the dynamics of closed-loop supply chains with capacity constraints. Computers $\&$ Industrial Engineering 128: 91-103.

[10] Fishman, C. 2006. The Wal-Mart effect: how the world's most powerful company really works- and how it's transforming the American economy. New York: Penguin Press. 
[11] Heese, H.S. and E. Kemahlioğlu-Ziya. 2016. Don't ask, don't tell: Sharing revenues with a dishonest retailer. European Journal of Operational Research 248 (2): 580-592.

[12] Helper, C., L. Davis and W. Wei. 2010. Impact of demand correlation and information sharing in a capacity constrained supply chain with multiple-retailers. Computers $\&$ Industrial Engineering 59: 552-560.

[13] Huang, Y., J. Hung, and J. Ho. A sutudy on information sharing for supply chains with multiple suppliers. Computers \& Industrial Engineering 104: 114-123.

[14] Lin, Q. and J. He. 2019. Supply chain contract design considering the supplier's asset structure and capital constraints. Computers \& Industrial Engineering 137. doi: https://doi.org/10.1016/j.cie.2019.106044.

[15] Narayanan, V. G., A. Raman, and J. Singh. 2005. Agency costs in a supply chain with demand uncertainty and price competition. Management Science 51 (1):120-132.

[16] Rached, M., Z. Bahroun, and J. Campagne. 2015. Assessing the value of information sharing and its impacts on the performance of the various partners in supply chains. Computers \& Industrial Engineering 88: 237-253.

[17] Simchi-Levi, D. and Y. Zhao. 2003. The value of information sharing in a two-stage supply chain with production capacity constraints. Naval Research Logistics 50: 888916.

[18] Titah, R., S. Shuraida, and Y. Rekik. 2016. Integration breach: Investigating the effect of internal and external information sharing and coordination on firm profit. International Journal of Production Economics 181:34-47.

[19] Welker, G., T. van der Vaart, and D. van Donk. 2008. The influence of business conditions on supply chain information-sharing mechanisms: A study among supply chain links of SMEs. International Journal of Production Economics 113: 706-720. 
[20] Yu, M., S. Ting, and M. Chen. 2010. Evaluating the cross-efficiency of information sharing in supply chains. Expert Systems with Applications 37: 2891-2897. 


\section{Figures}

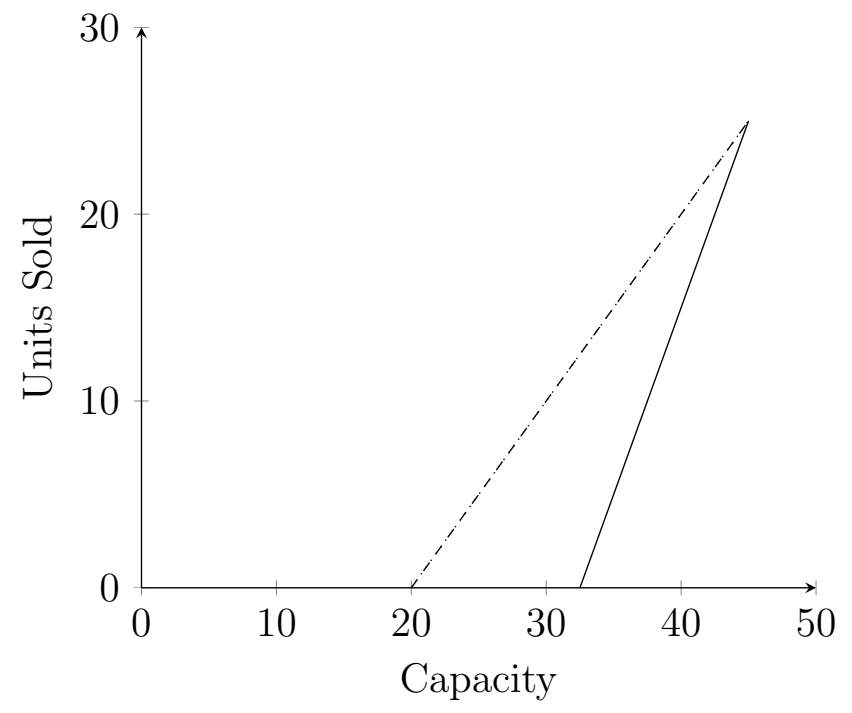

Fig. 1. Units Sold Under the Three Contracts

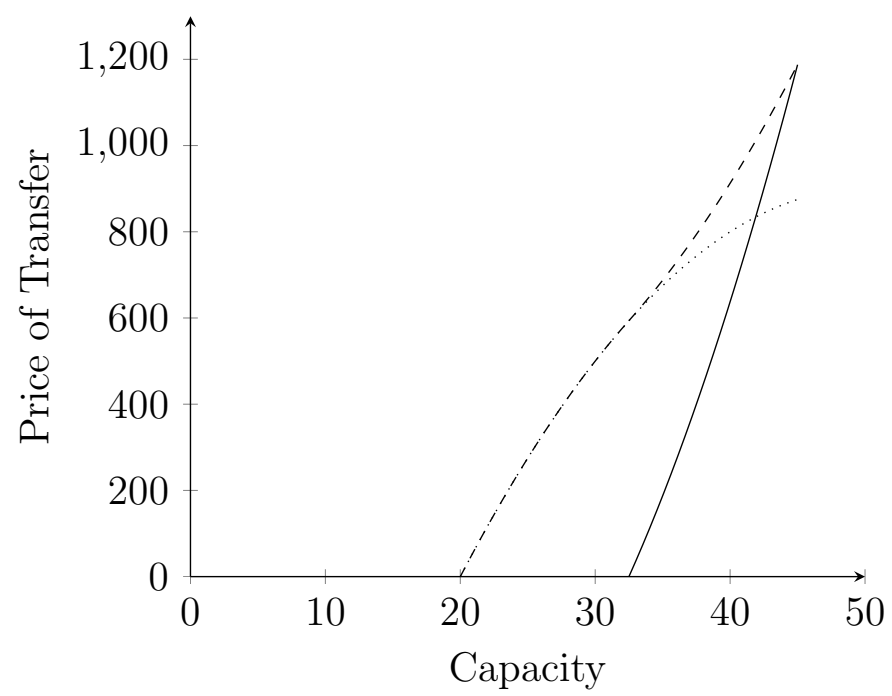

Fig. 2. Prices of Sale Under the Three Contracts 


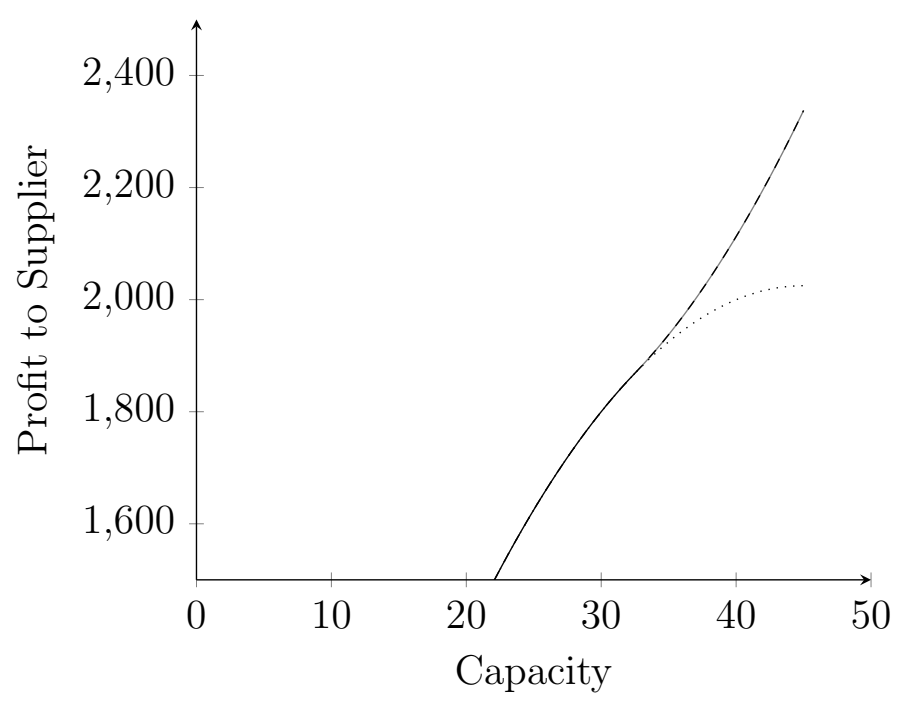

Fig. 3. Supplier Profits Under the Three Contracts

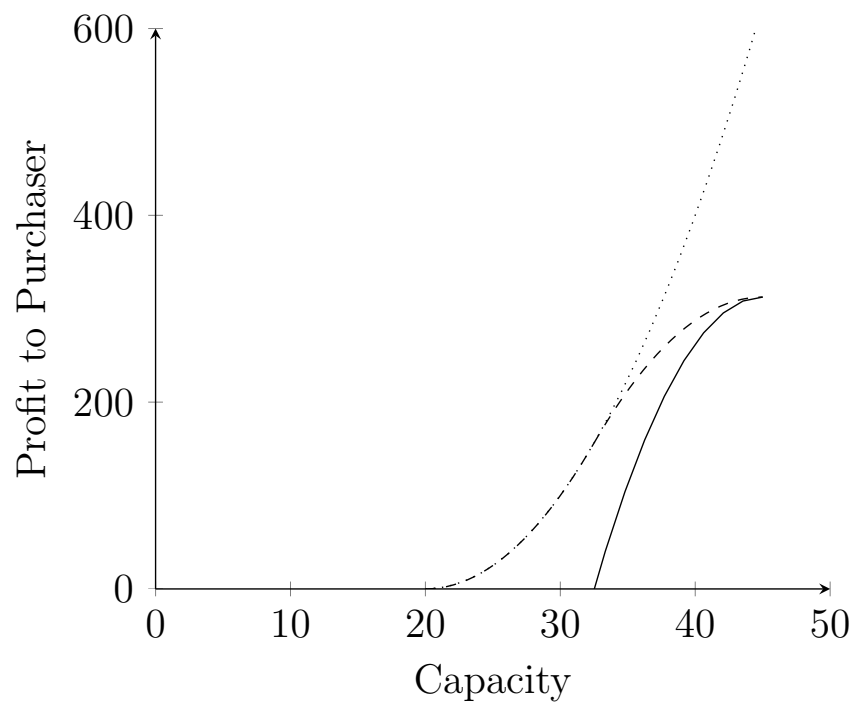

Fig. 4. Purchase Profits Under the Three Contracts 


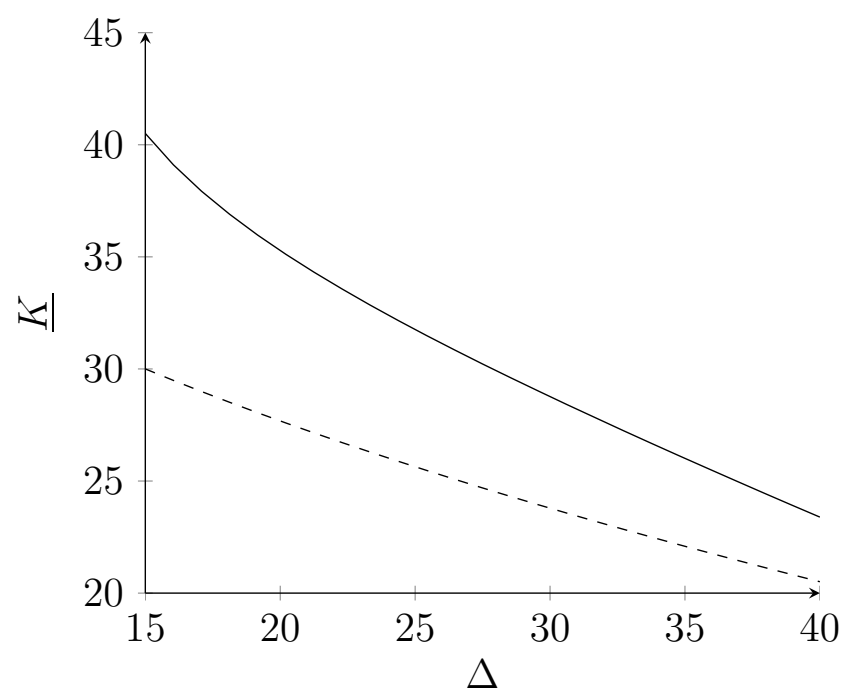

Fig. 5. Investment in Capacity as a Function of $\Delta$

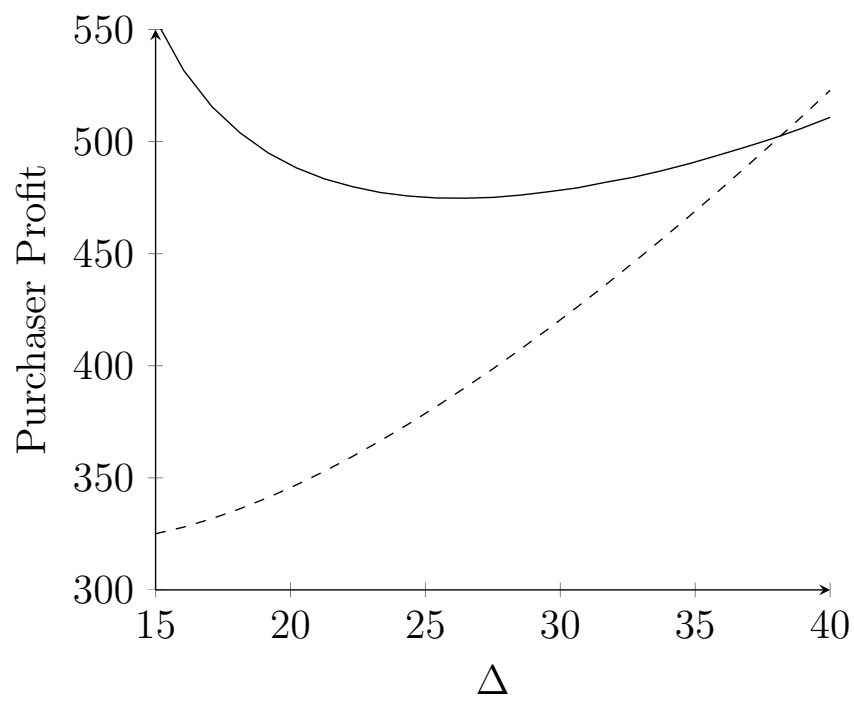

Fig. 6. Purchaser Profits as a Function of $\Delta$ 


\section{Appendix}

\section{Proof of Proposition 1}

We begin by computing the price, $T(y(K))$, that is paid to the supplier for supplying $y(K)$ units to the purchaser when observing capacity $K$ and reporting capacity, $\hat{K}=K$ for all capacity levels where the supplier has no idle capacity, $K \leq K_{1}$.

The supplier's rent in equation (4) is given by:

$$
r(\hat{K} \mid K)=T(y(\hat{K}))+A(K-y(\hat{K}))-b(K-y(\hat{K}))^{2}-c K-\Pi(K)
$$

Let $r(\hat{K} \mid K)$ denote the report, $\hat{K}$ when the supplier observes $K$.

Incentive compatibility requires:

$$
r_{1}(K \mid K)=\frac{\partial r(K \mid K)}{\partial \hat{K}}=0
$$

As this holds for any capacity level, $K$, the total derivative of $r(\cdot)$ with respect to the report and $K$ is: $r^{\prime}(K)=r_{1}(K \mid K)+r_{2}(K \mid K)=r_{2}(K \mid K)$. This expression states that the changes in the supplier's rent as a function of changes in both the report when the supplier is reporting honestly (the first $K$ ) and the actual $K$ that is observed is equal to the sum of the partial derivatives of the rent with respect to the honest report and with respect to the observed $K$. Since the supplier is reporting honestly $(\hat{K}=K)$, we can simplify the notation to $r^{\prime}(K)$. In addition, as a result of our truth-telling constraint, (33), this simplifies to the partial of the rent with respect to the actual $K$. As a result,

$$
r^{\prime}(K)=-2 b(K-y(K))-c-\Pi^{\prime}(K)=2 b y(K)
$$

In order to obtain an expression for $r(K)$, we integrate $(34)$. 


$$
r(K)=\int_{\underline{K}}^{K} 2 b y(k) d k+r(0)=\int_{\underline{K}}^{K} 2 b y(k) d k
$$

Next, we substitute (35) into (32) to obtain:

$$
T(y(K))=\int_{\underline{K}}^{K} 2 b y(K) d k+A y(K)-b K^{2}+b(K-y(k))^{2}
$$

Substituting into the purchaser's objective function for this payment, the purchaser's problem becomes:

$$
\max _{y(K)} \int_{\underline{K}}^{\underline{K}+\Delta}\left[V y(K)-A y(K)-b(K-y(K))^{2}-\int_{\underline{K}}^{\underline{K}+\Delta} 2 b y(k) d k+b K^{2}\right] \frac{1}{\Delta} d K
$$

Integrating by parts, (37) becomes:

$$
\max _{y(K)} \int_{\underline{K}}^{\underline{K}+\Delta}\left[V y(K)-A y(K)-b(K-y(K))^{2}-2 b y(K)(\underline{K}+\Delta-K)+b K^{2}\right] \frac{1}{\Delta} d K
$$

Point-wise optimization provides the first order condition:

$$
V-A+2 b(K-y(k))-2 b(\underline{K}+\Delta-K)=0
$$

which implies:

$$
y(K)=2 K-\frac{A-V}{2 b}-(\underline{K}+\Delta)
$$

Substituting (40) into (36), we obtain the equilibrium value of $T(y(K))$ in (10). 


\section{Proof of Proposition 2}

The supplier's reservation profit is given by (11) and the price must satisfy (12). We know that $T$ will be the minimum value such that (12) is satisfied. That value is computed as:

$$
\begin{gathered}
T=\frac{1}{4 b}(A-2 b K+V)(V-A+2 b K) \quad \text { if } \quad K \in\left[\frac{A-V}{2 b}, \frac{A-c}{2 b}\right], \quad \text { and } \\
T=\frac{1}{4 b}\left(V^{2}-c(2 A-c-4 b K)\right) \quad \text { if } \quad K>\frac{A-c}{2 b}
\end{gathered}
$$

Substituting (41) into the purchaser's profit of $V y-T$ yields:

$$
y(V-A+2 b K-b y)
$$

Therefore, if $K \leq \frac{A-c}{2 b}$, the purchaser chooses

$$
\begin{gathered}
y^{*}=K-\frac{A-V}{2 b} \\
T^{*}=\frac{(A-2 b K+V)(-A+2 b K+V)}{4 b}
\end{gathered}
$$

On the other hand, substituting (42) into $V y-T$ yields:

$$
V y+(K-y)(A-b(K-y))-c K-\frac{(A-c)^{2}}{4 b}
$$

The first order condition for choosing $y$ in (46) is: 


$$
V-A+2 b(K-y)=0
$$

which implies that $y^{*}=K-\frac{A-V}{2 b}$ as in (44). Substituting this value of $y$ into (42) implies that if $K>\frac{A-c}{2 b}$,

$$
T^{*}=\frac{1}{4 b}\left(V^{2}-c(2 A-c-4 b K)\right)
$$

\section{Proof of Corollary 1}

From (9), $y^{S C}=2 K-(\underline{K}+\Delta)-\frac{A-V}{2 b}$ and from (13), $y^{F I}=K-\frac{A-V}{2 b}$.

$y^{F I}-y^{S C}=(\underline{K}+\Delta)-K>0$.

\section{Proof of Proposition 3}

For $K \leq \frac{A-c}{2 b}$, the profit to the supplier under the Supply Chain contract is computed as

$$
K(A-b K-c)+r(\hat{K} \mid K)
$$

where $r(\hat{K} \mid K)$ is the information rent to the supplier that is characterized by (8). For $K>\frac{A-c}{2 b}$, the profit to the supplier is computed as:

$$
\frac{(A-c)^{2}}{4 b}+r(\hat{K} \mid K)
$$

Under the Full Information contract, the supplier's profit is computed as:

$$
K(A-b K-c) \quad \text { if } \quad K \leq \frac{A-c}{2 b} \text { and }
$$




$$
\frac{(A-c)^{2}}{4 b} \text { otherwise. }
$$

By construction, $r(\hat{K} \mid K) \geq 0$ for all $K$ so the supplier earns higher profits under the Supply Chain contract than under the Full Information contract.

Using the same logic, the purchaser's profits, under the Full Information contract, for $K \leq \frac{A-c}{2 b}$ are:

$$
\frac{1}{4 b}(A-V-2 b K)^{2}
$$

For $K>\frac{A-c}{2 b}$, these profits are:

$$
\frac{1}{4 b}(V-c)(V+c+4 b K-2 A) .
$$

For $K \leq \frac{A-c}{2 b}$, the purchaser's profits under the Supply Chain contract are computed as:

$$
\frac{1}{4 b}(A-V-2 b K)^{2}-r(\hat{K} \mid K)-b(\underline{K}+\Delta-K)^{2}
$$

For $K>\frac{A-c}{2 b}$, this profit is computed as:

$$
\frac{1}{4 b}(V-c)(V+c+4 b K-2 A)-r(\hat{K} \mid K)-b(\underline{K}+\Delta-K)^{2}
$$

By observation, we see that (53) is strictly greater than (55) and (54) is strictly greater than (56).

\section{Proof of Corollary 2}


From $(10), T^{S C}(\hat{K})=\frac{1}{8 b}(3 V+A+2 b(2 \hat{K}-3(\underline{K}+\Delta)))(V+2 b(2 \hat{K}-(\underline{K}+\Delta))-A)$ and from $(23), T^{H}(K)=\frac{(A-4 b K+2 b(\underline{K}+\Delta)-V)^{2}}{8 b}+\frac{(V+A-2 b K)(V-A+2 b k)}{4 b}$ for $K \in\left(K^{S C}, \underline{K}+\Delta\right)$. Since the supplier reports truthfully under the Supply Chain contract, $T^{S C}(K)=T^{S C}(\hat{K})$. Subtracting $T^{S C}(K)$ from $T^{H}(K)$, we obtain:

$$
T^{H}(K)-T^{S C}(K)=(\underline{K}+\Delta-K)(V-b(\underline{K}+\Delta-K))
$$

Note, that $T^{S C}\left(K^{S C}\right)=0, T^{H}\left(K^{S C}\right)>0$, and (57) is increasing in $K$. Hence, for all $K \in\left(K^{S C}, \underline{K}+\Delta\right), T^{H}(K)>T^{S C}(K)$.

\section{Proof of Proposition 5}

By construction, the supplier is indifferent between the Supply Chain contract and the Hybrid contract. We must only show, therefore, that the purchaser achieves strictly higher profits from the Hybrid contract.

For $K \in\left[K^{F I}, K^{S C}\right], y^{H}>y^{F I}$ so the purchaser obtains strictly greater profits in this range. Suppose $K>K^{S C}$. We compute the payoff to the purchaser under the Supply Chain contract as:

$$
\frac{1}{8 b}(A+4 b K-6 b(\underline{K}+\Delta)-V)(A-4 b K+2 b(\underline{K}+\Delta)-V)
$$

Under the Hybrid contract, the payoff to the purchaser over this region is computed as:

$\frac{1}{8 b}\left(A^{2}-4 b^{2}\left(2 K^{2}-4 K(\underline{K}+\Delta)+(\underline{K}+\Delta)^{2}\right)+4 b(\underline{K}+\Delta) V+V^{2}-2 A(2 b(\underline{K}+\Delta)+V)\right.$

Subtracting (58) from (59), we obtain the incremental profit to the purchaser, over the range $K \in\left[K^{S C}, \underline{K}+\Delta\right]$, of the Hybrid contract relative to the Supply Chain contract: 


$$
b(\underline{K}+\Delta-K)^{2}>0
$$

\section{Proof of Proposition 6}

We begin by computing the investment choice that the supplier makes: $\underline{K}^{F I}$ under the Full Information contract and $\underline{K}^{H}$ under the Hybrid contract. To compute this, we compute the expected payoff to the supplier under each of these two contracts. We begin by computing the expected payoff to the supplier under the Full Information contract.

$$
\begin{aligned}
& \int_{K^{F I}}^{\underline{K}^{F I}+\Delta}\left(T^{F I}+\left(K-y^{F B}\right)\left(A-b\left(K-y^{F B}\right)-c\right)\right) \frac{1}{\Delta} d K+ \\
& \int_{\underline{K}^{F I}}^{K^{F I}}(K(A-b K-c)) \frac{1}{\Delta} d K-\underline{K}^{F I} Z
\end{aligned}
$$

The expression in (61) is evaluated as:

$$
\begin{aligned}
& \frac{1}{24 b^{2} \Delta}\left(-A^{3}+c^{3}+12 b^{2} c\left(\underline{K}^{F I}\right)^{2}+6 b c^{2}\left(\underline{K}^{F I}+\Delta\right)+3 A^{2}\left(c+2 b\left(\underline{K}^{F I}+\Delta\right)\right)\right)+ \\
& \frac{1}{24 b^{2} \Delta}\left(-3 A\left(c^{2}+4 b^{2}\left(\underline{K}^{F I}\right)^{2}+4 b c\left(\underline{K}^{F I}+\Delta\right)\right)+8 b^{2} \underline{K}^{F I}\left(b\left(\underline{K}^{F I}\right)^{2}-3 \Delta Z\right)\right)
\end{aligned}
$$

The first order condition for the optimality of (62) as a function of $\underline{K}^{F I}$ is:

$$
\frac{1}{4 b \Delta}\left(A^{2}+c^{2}+4 b c \underline{K}^{F I}-2 A\left(c+2 b \underline{K}^{F I}\right)+4 b\left(b\left(\underline{K}^{F I}\right)^{2}-\Delta Z\right)\right)=0
$$

Which is satisfied by:

$$
\underline{K}^{F I}=\frac{A-c}{2 b}-\sqrt{\frac{\Delta Z}{b}}
$$


We employ the same approach for the supplier's choice of $\underline{K}^{H}$ except that we take the first order condition of the supplier's expected payoff under the Supply Chain contract, which will yield an identical value of $\underline{K}$ since the payoffs, by construction, are identical for every realization of $K$. Using this approach, the optimal value of $\underline{K}^{H}$ is:

$$
\underline{K}^{H}=\frac{A-V}{2 b}+3 \Delta-2 \sqrt{\frac{\Delta(c+3 b \Delta-V+Z)}{b}}
$$

Next, we compute the purchaser's expected payoff given the supplier's choice of $\underline{K}^{F I}$ or $\underline{K}^{H}$.

Note that the purchaser's expected payoff under the Full Information contract can be computed as:

$$
\frac{1}{4 b \Delta} \int_{\underline{K}^{F I}}^{\underline{K}^{F I+\Delta}}(2 b K-A+V)^{2} d K
$$

Under the Hybrid contract, the purchaser's expected payoff is:

$$
\frac{1}{4 b \Delta} \int_{\underline{K}^{H}}^{\underline{K}^{H}+\Delta}(2 b K-A+V)^{2} d K-\int_{K^{S C}}^{\underline{K}^{H}} r(\hat{K} \mid K) \frac{1}{\Delta} d K
$$

We will substitute the values of $\underline{K}^{F I}$ and $\underline{K}^{H}$ into (66) and (67) and then subtract (66) from (67). If that difference is positive, then the purchaser obtains a higher expected payoff under the Hybrid contract with its corresponding value of $\underline{K}^{H}$ than under the Full Information contract with $\underline{K}^{F I}$. This difference is computed as:

$$
\begin{aligned}
& \frac{1}{12 b^{2}}\left(80 b^{3} \Delta^{2}+8(c-V+Z) \sqrt{b^{3} \Delta(c+3 b \Delta-V+Z)}+6 b^{2} \Delta(c-V-2 Z+2 \sqrt{b \Delta Z})\right)- \\
& \frac{1}{4 b}\left((V-c)^{2}-4(V-c) \sqrt{b \Delta Z}+16 \Delta \sqrt{b^{3} \Delta(c+3 b \Delta-V+Z)}\right)+\frac{(V-c-2 \sqrt{b \Delta Z})^{3}}{24 b^{2} \Delta}
\end{aligned}
$$


To simplify this expression, we express $Z=\beta(V-c)$ and $\Delta=\alpha(V-c)$. We are merely choosing $(V-c)>0$ as a scaling factor with which we express two positive values.

Using these substitutions, we rewrite (68) as:

$$
\begin{aligned}
& \frac{(V-c)^{2}}{24 \alpha}\left(\sqrt{\alpha \beta}\left(-6+24 \alpha^{2}-8 \alpha(\beta-3)\right)+\sqrt{\alpha(3 \alpha+\beta-1)}\left(-96 \alpha^{2}+16 \alpha(\beta-1)\right)\right) \\
& +\frac{(V-c)^{2}}{24 \alpha}\left(1-6 \alpha-12 \alpha^{2}+160 \alpha^{3}+12 \alpha \beta-24 \alpha^{2} \beta\right)
\end{aligned}
$$

This expression is not well-behaved, but since $\frac{(V-c)^{2}}{24 \alpha}>0$ and since the remainder of the expression in (69) involves only two positive parameters, we can characterize, by numerical analysis, the conditions under which (69) is positive. For $\beta$ sufficiently small (less than $\frac{1}{2}$ ), the expression is positive as long as $\alpha$ is sufficiently small (but note that $\alpha$ must be greater than $\frac{1-\beta}{3}$ in order for $\underline{K}^{H}$ to be defined). Details are available from the authors. 